\title{
Proof of CONCEPT: Pozzolan BRICKS FOR SALINE WATER EVAPORATIVE COOLING IN CONTROLLED ENVIRONMENT AGRICULTURE
}

\author{
R. M. Lefers, P. A. Davies, N. V. Fedoroff, N. Almadhoun, M. A. Tester, T. Leiknes
}

\section{AUTHOR'S UNFORMATTED COPY}

\author{
Citation: Applied Engineering in Agriculture. 34(6): 929-937. (DOI: 10.13031/AeA.13013) @2018
}

\begin{abstract}
The authors are Ryan M. Lefers, Post-Doctoral Fellow, King Abdullah University of Science and Technology, Thuwal, Saudi Arabia; Philip A. Davies, Reader in Mechanical Engineering and Design, Aston University, Birmingham, UK; Nina V. Fedoroff, Emeritus Evan Pugh Professor, Penn State University, State College, Pennsylvania, USA; Nassar Almadhoun, Engineer, Masader Engineering, Jeddah, Saudi Arabia, Mark A. Tester, Professor, King Abdullah University of Science and Technology, Thuwal, Saudi Arabia, and T. Leiknes, Professor, King Abdullah University of Science and Technology, Thuwal, Saudi Arabia. Corresponding author: Ryan Lefers, King Abdullah University of Science and Technology, Building 4 Al-Jazri, Level 4, Area \#4255 (Seaside), Desk \#WS-01, Thuwal, Makka, 23955-6900, Kingdom of Saudi Arabia; Phone: +966 (0)12 808 2273; e-mail: ryan.lefers@kaust.edu.sa.
\end{abstract}

\section{AbSTRaCt.}

Control of indoor temperature and humidity is of critical concern for controlled environment agriculture systems in hot, arid regions. Evaporative cooling is a technology utilized for energy-efficient cooling and humidification of these systems. However, the evaporative cooling process consumes considerable amounts of water, as much as 80-90\% of the water footprint for indoor food production in these regions. The use of saline water in place of fresh water in evaporative cooling systems offers a potential solution for greatly improving the sustainability of these systems. However, the use of saline water in industry-standard cellulose pad systems can cause premature clogging of the porous medium, leading to system failure and the need for porous media replacement. A new evaporative cooling technology consisting of crushed pozzolan volcanic rock formed into porous bricks was evaluated for use in controlled environment agriculture systems using saline water. Two brick designs were tested for proof of concept cooling of commercial-scale greenhouses. Temperature-based cooling efficiencies of the bricks were achieved that are comparable to cellulose pads. In addition, the pozzolan-based bricks showed impressive resistance to saline water and harsh environments, requiring no replacement over the duration of the experimental trials. The integration of the pozzolan evaporative cooling systems using sea or brackish water with a water-saving growing technology, such as recirculating aquaponics or hydroponics, shows promise for reducing the fresh water footprint of food raised indoors in hot, dry environments by as much as $80-90 \%$. 
Evaporative cooling, pozzolan, controlled environment, salt, water conservation

31

\section{INTRODUCTION}

To grow crops in controlled environment agriculture (i.e. Greenhouses) in hot regions of the world, a measure of cooling is required to make the indoor environment suitable for crop production. The most widely-used method for greenhouse cooling worldwide is evaporative cooling. Evaporative cooling is a technology that reduces the temperature of air while increasing the relative humidity level (Dağtekin, Karaca, \& Y1ldız, 2009; Koca, Hughes, \& Christianson, 1991; Malli, Seyf, Layeghi, Sharifian, \& Behravesh, 2011; Sabeh, 2007). Humidity is added to the incoming air by forcing air through a wetted porous media that has high surface area per unit volume. As air comes into contact with the wet surface, water moves from a liquid state into its gaseous state. Heat energy from the incoming air is transferred to the water during the state change from liquid to gas to overcome the latent heat of vaporization. When this happens, the air exits the system with a lower temperature and a higher humidity. Evaporative coolers are known by a number of common names, including swamp cooler, desert cooler, pad and fan, adiabatic cooler and others.

Evaporative cooling has a number of differences when compared with traditional vapor compression air conditioning (Table 1). Of significance for evaporative cooling are the lower energy use, the higher water use, and how the cooling potential varies in non-humid vs. humid climates. Effective cooling in terms of a large temperature drop can only be realized if the air to be cooled by the evaporative process has a low incoming relative humidity.

Table 1. Comparison of cooling strategies. In this table, "air conditioning" is mechanical vapor compression.

\begin{tabular}{cc} 
Evaporative Cooling & Air Conditioning \\
\hline +Energy efficient & -Higher energy usage \\
$\sim$ Effective in non-humid climates & + Effective in any climate \\
+ Fresh outdoor air & $\sim$ Air recirculation \\
$\sim$ Adds moisture to the air & $\sim$ Removes moisture \\
-High water use & +No water use \\
+ Economical to operate & -Higher cost to operate \\
\hline
\end{tabular}

Cellulose pads are the current industry standard in evaporative cooling technology. These plasticized cardboard pads offer a very high surface area per unit volume and are easy to wet because of their natural wicking properties. In addition, they are relatively light and their cost is low ( $\sim 50-\$ 75$ USD per square meter). New pads offer excellent humidification and cooling of dry, hot air, with an estimated cooling efficiency of 70-90\%, depending on air speed and pad properties. (Koca et al., 1991; Malli et al., 2011) However, a disadvantage of cellulose pads is that they may clog and lose cooling efficiency over time if 
they are not maintained properly (Figure 1). Airborne dust and particulates mix with salts in the water to form crusts and cements that block airflow through the CP. Depending on the environment and the maintenance provided, a typical cellulose pads lasts from 3 months to 10 years, a conclusion based on anecdotal evidence from users at sites in the Middle East and North America. Other types of evaporative cooling media exist on the market, including porous plastic sheets, plastic balls, woven ropes, palm fronds, and other materials. (Ahmed, Abaas, Ahmed, \& Ismail, 2011; Gunhan, Demir, \& Yagcioglu, 2007; He \& Hoyano, 2010; Johnson, Yavuzturk, \& Pruis, 2003; C.-M. Liao \& Chiu, 2002; C. M. Liao, Singh, \& Wang, 1998) However, none of these materials has as large of a market share in controlled environment agriculture as cellulose pads.

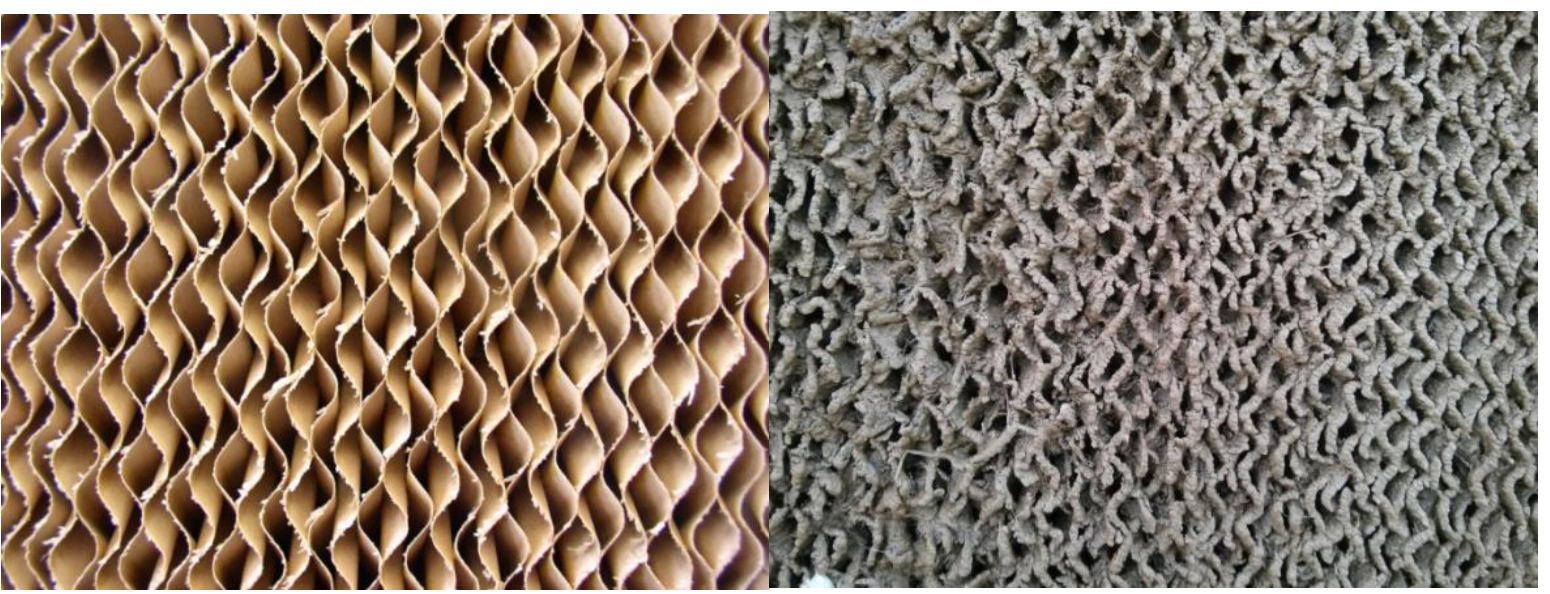

Figure 1. A new and a 4-year old cellulose pad installed at a greenhouse on the KAUST campus in Thuwal, KSA. The 4-year old pad is blocked with hard crusts of dust and salts, and requires replacement.

Evaporative cooling is estimated to contribute as much as $55-90 \%$ of the total water footprint of crops grown in greenhouses. (Lefers et al., 2016; Sabeh, 2007) In fact, when the water use from evaporative cooling is included in the total water footprint of the crop produced, the actual water input per unit of output is approximately equal to that of the same crop grown outdoors. (Sabeh, 2007) A possible solution is to replace the fresh water used in evaporative cooling with either sea or brackish water. (Davies \& Paton, 2004; Dawoud, Zurigat, Klitzing, Aldoss, \& Theodoridis, 2006; Ghaffour, Reddy, \& Abu-Arabi, 2011; Goosen et al., 2003; Mahmoudi, Spahis, Abdul-Wahab, Sablani, \& Goosen, 2010; Mahmoudi et al., 2009; Sablani, Goosen, Paton, Shayya, \& Al-Hinai, 2003; Tahri, Douani, Abdul-Wahab, Amoura, \& Bettahar, 2013; Zamen, Amidpour, \& Firoozjaei, 2013) Brackish groundwater and sea water resources are wide spread, therefore, the use of these resources is applicable around the globe. (Weert, Reckman, Gun, \& Kempen, 2009) However, the use of a high salinity water source carries with it the risk of salt precipitation during the evaporative cooling process if the salinity is not monitored and managed closely. As water evaporates, the salt concentration in the solution increases, ultimately precipitating to form solid crystals if the concentration of any salt reaches its crystallization point. In addition, the mixing of airborne dust, particularly silica, with salts such as 
calcium carbonate in sea or brackish water, can speed the formation of solids such as vaterite and calcite. (Lakshtanov \& Stipp, 2010) (Kellermeier et al., 2013)

The clogging of evaporative cooling media is a concern for two reasons. First, the size of the porous media voids will be reduced, increasing the velocity of the air that must pass through the voids in order to maintain the same overall volume airflow rate. This increased velocity leads to increased pressure losses, corresponding to higher fan energy usage. The increased velocity also leads to a shorter air/wetted media contact time, reducing the efficiency of the evaporative cooling and increasing the expected output temperature. Second, the clogged medium will in time require replacement, placing an additional financial, management and time burden upon the owner.

Due to the increased risk of evaporative cooling media clogging, along with the additional management burden of closely monitoring the concentration of salts in the evaporative cooling solution, many growers have chosen to not use saline water. For example, in areas of Saudi Arabia where brackish water is readily available, many growers have instead chosen to install small-scale desalination plants to desalinate the brackish water and use the resulting fresh water in the evaporative cooling process. This situation is not limited to Saudi Arabia alone, many areas around the globe face similar challenges. The desalination of the brackish water before use in the evaporative cooler increases the energy consumption, as electrical energy is commonly used in connection with reverse osmosis systems for desalination of these brackish water sources.

\section{MATERIALS AND METHODS}

To address concerns related to the clogging of cellulose pads evaporative cooling media, and to further enable the use of brackish and/or seawater for agriculture, a novel system was developed and tested for evaporative cooling, as shown in Figure 2. (Al-Madhoun, 2016) Of special importance in the development of the new evaporative cooling media was long life, resistance to harsh environments, local availability, cost, ease of construction, and ease of management. To meet these needs, porous void media bricks were fashioned from a local pozzolan volcanic rock. Pozzolan rock is widely used in the Portland cement industry, and is known for its exceptional resilience to harsh environments and long life (al-Swaidani, Aliyan, \& Adarnaly, 2016; Khan \& Alhozaimy, 2010). The pozzolan rock was sourced from scoria from the local Harrat Rahat (Saudi Arabia), crushed and formed into permeable bricks with intentional voids for air and liquid passage. The scoria from the Harrat Rahat has been recommended for use in pozzolanic concrete as lightweight aggregate, thermal insulating material, filter material, and for other architectural applications. (Moufti, Sabtan, El-Mahdy, \& Shehata, 2000) Although the technology was applied locally using pozzolan from Harrat Rahat, the technology can be applied globally as well, as natural deposits of these materials are 
available around the world. (Snellings, Mertens, \& Elsen, 2012) Based upon the expected benefits of the pozzolan material, permeable bricks of pozzolan were designed for evaporative cooling applications and a patent was applied for. The technology was patent-pending at the time of writing of this manuscript. (Al-Madhoun, 2016)

Pozzolan Brick Evaporative Cooler

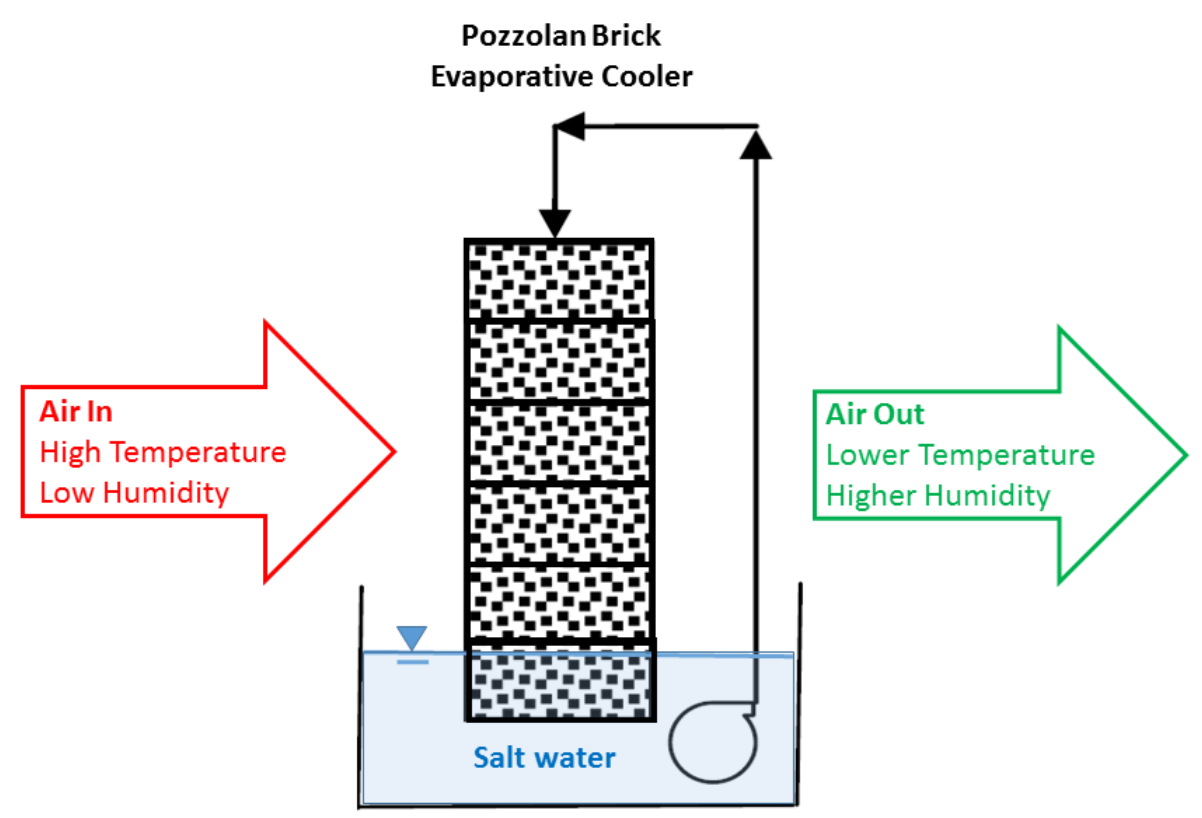

105

Figure 2. Proposed evaporative cooling system for use with brackish water sources.

Two types of pozzolan bricks were manufactured and supplied for proof of concept testing in evaporative coolers. Both types of bricks were manufactured using crushed pozzolan. From the crushed material, fine particles were removed to provide additional porosity while large particles were removed to ensure a smoother finish. Pozzolan cement was used as the binder for the bricks. Type 1 (T1) bricks (Figure 3) were manufactured using a hand press with standard $2 \mathrm{~cm}$ diameter cylindrical holes and outer brick dimensions of $200 \mathrm{~mm} \times 100 \mathrm{~mm}$ x $100 \mathrm{~mm}$. Type 2 (T2) bricks (Figure 4) were manufactured using an egg laying type mechanical press with conical holes for air passage $(3 \mathrm{~cm}$ inlet, $2 \mathrm{~cm}$ outlet) and have outer brick dimensions of $400 \mathrm{~mm} \times 200 \mathrm{~mm} \times 200 \mathrm{~mm}$. T2 bricks were designed to have more surface area for air/liquid contact in the conical air passage holes, with the expectation that this increase in surface area would lead to more liquid evaporation and therefore a higher cooling efficiency. T2 bricks have $25 \%$ more surface area for air/liquid contact per unit volume than T1 bricks. 

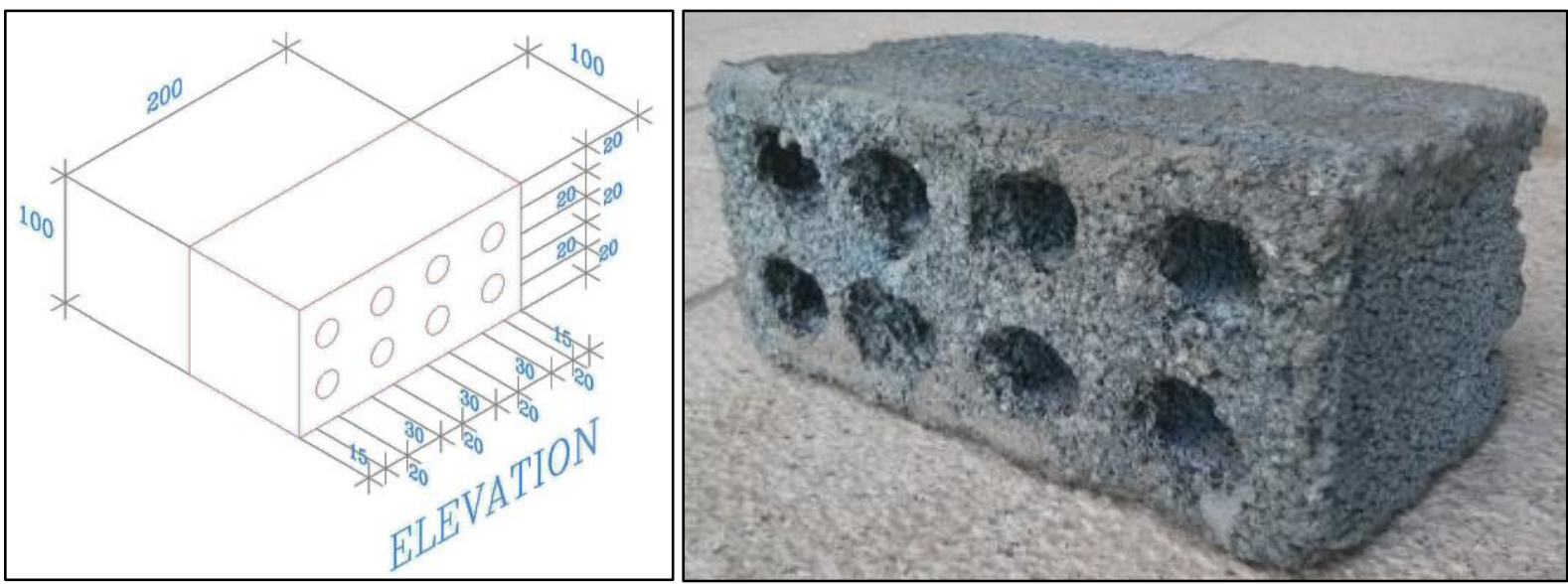

Figure 3. Type 1 pozzolan bricks for brackish water evaporative cooling. Holes for air passage are cylindrical. The brick structure is permeable to allow liquid passage through the body of the brick. Units are in $\mathbf{m m}$.

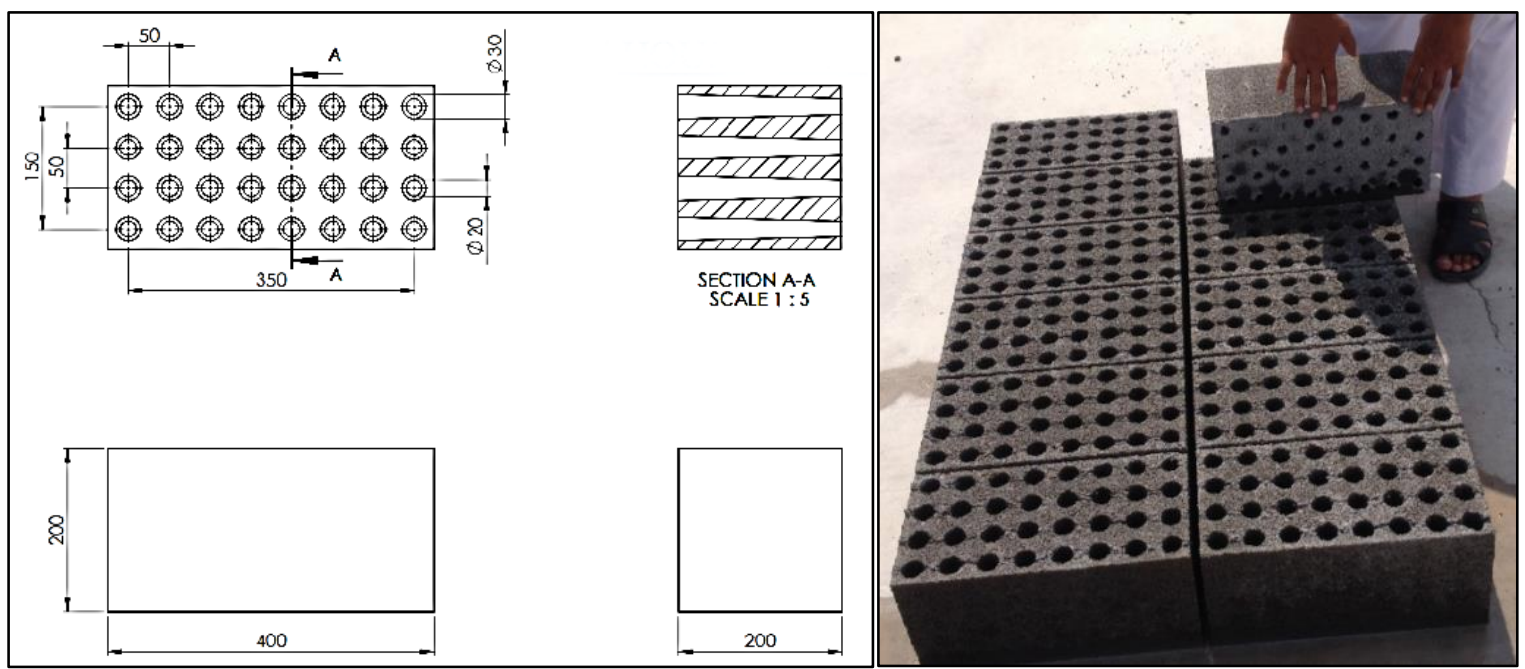

Figure 4. Type 2 pozzolan bricks for brackish water evaporative cooling. Holes for air passage are conical, allowing for a $25 \%$ increase in surface area for air/liquid contact and evaporation as compared to the cylindrical holes in Type 1 bricks. Like Type 1 bricks, the brick structure is permeable to allow liquid passage through the body of the brick. Units are in $\mathrm{mm}$.

To prove the concept of using the pozzolan bricks for evaporative cooling with salt water, two sets of experiments were conducted (Table 2). The first evaporative cooling system was set up using T1 bricks (Figure 5). This system was constructed on the King Abdullah University of Science and Technology (KAUST) campus in Thuwal, Saudi Arabia and was supplied with saline sea water from a near-shore well, with salinity levels around $\sim 43$ parts per thousand (ppt). The scale of the system mirrored that found in field-scale Saudi Arabian agriculture systems, with an evaporative cooler length of $12 \mathrm{~m}$ and a height of $2 \mathrm{~m}$. The system included four rows of T1 bricks, each $100 \mathrm{~mm}$ wide with a $100 \mathrm{~mm}$ gap between each row of bricks $(700 \mathrm{~mm}$ total thickness). The fans and water pump in the KAUST system ran continuously at a constant speed. 


\begin{tabular}{|c|c|c|c|}
\hline Pozzolan Brick Tyne & Fxneriment location & Evaporative Cooler Face & Notes \\
\hline Type 1 & $\begin{array}{c}\text { KAUST, Thuwal, Saudi } \\
\text { Arabia }\end{array}$ & $24 \mathrm{~m}^{2}$ & $\begin{array}{l}\text { Seawater source liquid, hot and humid climate, } \\
40 \mathrm{~cm} \text { porous media thickness }\end{array}$ \\
\hline Type 2 & $\begin{array}{l}\text { Gharbiya Farms, near } \\
\text { Riyadh, Saudi Arabia }\end{array}$ & $11.6 \mathrm{~m}^{2}$ & $\begin{array}{l}\text { Brackish water source liquid, hot and dry } \\
\text { climate, } 40 \mathrm{~cm} \text { porous media thickness }\end{array}$ \\
\hline
\end{tabular}

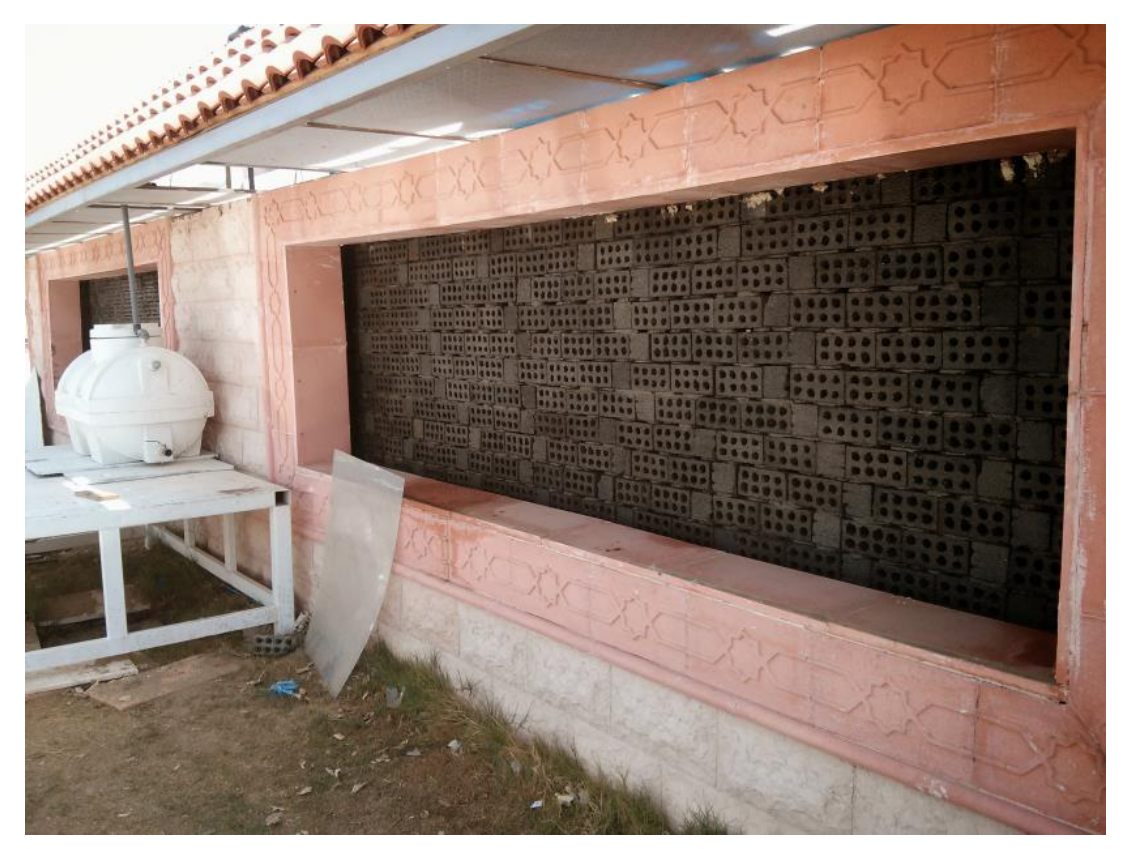

Figure 5. Type 1 pozzolan brick evaporative cooling system installed on the KAUST campus in Thuwal, Saudi Arabia.

T2 pozzolan bricks were used to construct an evaporative cooling system at the Gharbiya farms in the non-humid, central plateau near Riyadh, Saudi Arabia. The Gharbiya system was installed on an existing commercial greenhouse and operated using brackish water with a salinity of $\sim 3$ ppt. The T2 pozzolan system consisted of two sets of brick rows, each $200 \mathrm{~mm}$ thick with $60 \mathrm{~mm}$ of space in between rows, for a total system thickness of $460 \mathrm{~mm}$. The T2 pozzolan system was operated side by side in parallel with a traditional cellulose pads evaporative cooling system in a next door greenhouse (Figure 6 -7). Both the pozzolan and cellulose pads cooling systems at Gharbiya farms were connected to greenhouse climate control systems that turned on and off based on internal greenhouse conditions. When the climate control system sensed that greenhouse temperatures were over an operator-determined set point, the water pumps of the cooling system and the fans at the outlet of the greenhouse were turned on. When the greenhouse temperature then dropped to another user-set temperature, the control system turned the pumps and fans off until the greenhouse temperature again increased above the set point. Therefore, the cooling systems did not operate continuously, but on an as-needed basis. 

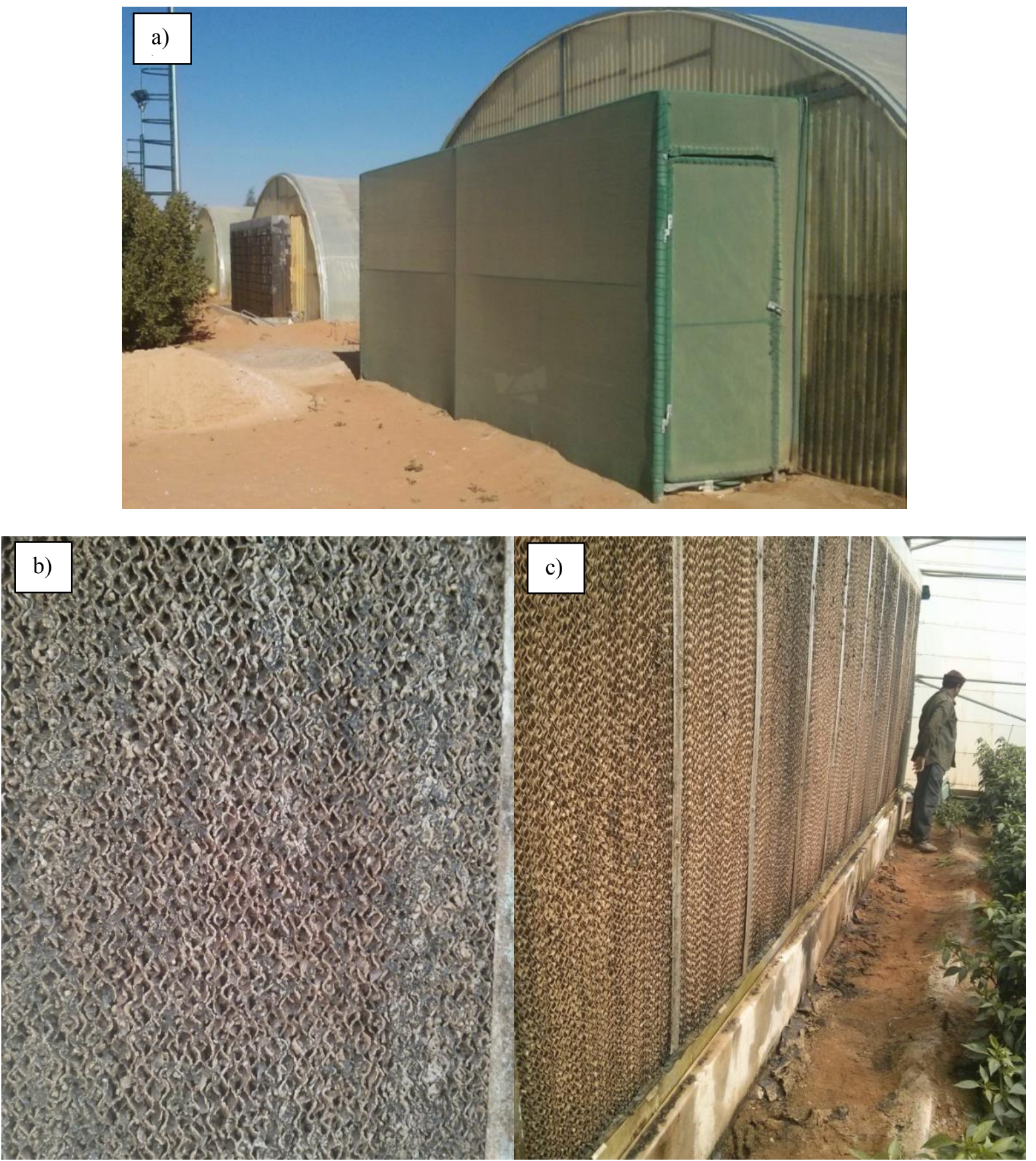

Figure 6. From top left to bottom right: a) outdoor view of evaporative cooling systems installed on experimental greenhouses at Gharbiya farms, near to Riyadh, Saudi Arabia. Greenhouse \#1 cellulose pad (right) and Greenhouse \#2 Type 2 pozzolan bricks (left). The cellulose pad system is located inside an intended dust filter (the visible green mesh enclosure.) b) close up view showing the condition of the in-use cellulose pad at the time of experimental testing and c) indoor view of the cellulose pad cooling system. Pictures taken Feb 24, 2015. 


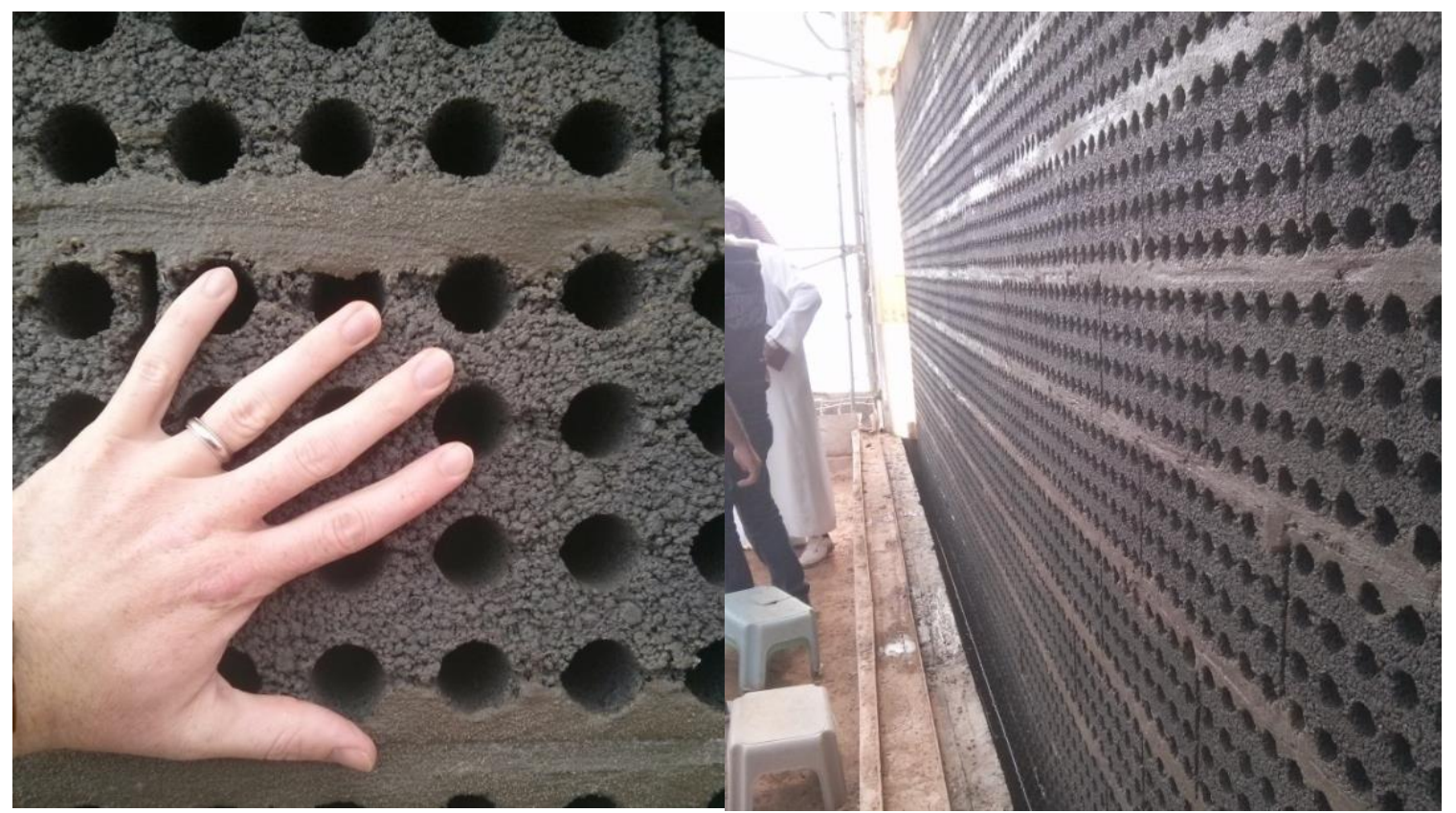

Figure 7. Experimental Gharbiya full scale system utilizing type 2 pozzolan bricks, installed at Greenhouse \#3. Picture taken Feb $24,2015$.

Parameters of interest for monitoring included the change in temperature and humidity, the air speed, and the pressure drop through the evaporative cooler. A Testo model 435-4 data logger equipped with an internal differential pressure sensor $( \pm 0.02$ $\mathrm{hPa}$ from 0 to $+2 \mathrm{hPa}, \pm 1 \%$ of measured value up to $+25 \mathrm{hPa}$ ) and connected temperature and relative humidity probes (model \# $06369736, \pm 0.3{ }^{\circ} \mathrm{C}, \pm 2 \% \mathrm{RH}$ ) and hot wire air velocity probe (model \#0635 1535, $\pm 0.03 \mathrm{~m} / \mathrm{s}+4 \%$ of measured value) were employed for data collection. The water flow rate over the bricks was adjusted such that the rate was increased until all bricks were consistently wet. Air flow in the system was driven by single speed greenhouse exhaust fans, which pulled air through the evaporative cooler in the same manner as is common in pad and fan greenhouses. The system air flow was calculated using the methods outlined in (Wheeler \& Both, 2002). A Vantage Pro2 weather station manufactured by Davis Instruments was utilized to capture outdoor and indoor climate data.

The cooling performance of the bricks was evaluated by the temperature based evaporative cooling efficiency ( $\eta$ ), as shown in Equation 1.

$$
\text { Temperature based evaporative cooling efficiency }(\eta)=\left(\frac{T_{d b}-T_{\text {exit }}}{T_{d b}-T_{w b}}\right) \times 100 \%
$$

Where

$\mathrm{T}_{\text {exit }}=$ dry-bulb temperature of air exiting the evaporative cooling bricks

$\mathrm{T}_{\mathrm{db}}=$ dry-bulb temperature of air entering the evaporative cooling bricks

$\mathrm{T}_{\mathrm{wb}}=$ wet-bulb temperature of air entering the evaporative cooling bricks 
All temperatures input into the cooling efficiency equation were supplied by data collected via the Vantage Pro2 weather station and the Testo Model 434-4 data logger with associated probes.

\section{RESULTS AND DISCUSSION}

\section{Evaporative Cooling Performance of Type 1 bricks}

Results of evaporative cooling using seawater and T1 bricks are shown in Table 3. Evaporative cooling efficiency of the bricks was evaluated on the basis of temperature (ๆT) (Koca et al., 1991; Malli et al., 2011). Because the bricks have a much lower percentage of void space than CPs, it is important to consider results against both face and void air velocity. Face velocity describes the velocity of air before entry into and after exit from the circular brick voids, i.e. the airflow divided by the total brick area in a 2D direction. Void velocity is the expected velocity within the designed brick voids, which is higher than the face velocity. Void velocity is the airflow divided by the total surficial void area in a 2D direction and is more appropriate for comparison with face velocities measured by other authors when using CPs.

Table 3. Comparison of KAUST system using seawater and type 1 pozzolan bricks with cellulose pad evaporative cooling system using fresh water. Type 1 Pozzolan Bricks

Seawater Evaporative Cooling System at KAUST

Cellulose Pads Freshwater Evaporative Cooling ${ }^{\text {a] }}$

\begin{tabular}{|c|c|c|}
\hline & & \\
\hline Number of porous media rows & 4 & 1 \\
\hline Total porous media thickness & $40 \mathrm{~cm}$ & $10 \mathrm{~cm}$ \\
\hline Space between rows & $10 \mathrm{~cm}$ & Not Applicable \\
\hline Total system thickness & $70 \mathrm{~cm}$ & $10 \mathrm{~cm}$ \\
\hline Face air velocity & $0.5 \mathrm{~m} \mathrm{~s}^{-1}$ & $3.9 \mathrm{~m} \mathrm{~s}^{-1}$ \\
\hline Pressure drop & $17 \mathrm{~Pa}$ & $87 \mathrm{~Pa}$ \\
\hline Void air velocity & $3.9 \mathrm{~m} \mathrm{~s}^{-1}$ & NA \\
\hline Temperature based cooling efficiency & $52 \%$ & $70 \%$ \\
\hline Pressure drop/media thickness & $0.43 \mathrm{~Pa} \mathrm{~cm}^{-1}$ & 8.7 $\mathrm{Pa} \mathrm{cm}^{-1}$ \\
\hline Cooling efficiency/media thickness & $1.3 \% \mathrm{~cm}^{-1}$ & $7.0 \% \mathrm{~cm}^{-1}$ \\
\hline
\end{tabular}

${ }^{[a]}$ Literature results (Koca et al., 1991).

As can be seen from Table 3, the experimental T1 pozzolan system as constructed at KAUST was not as efficient in terms of temperature-based cooling efficiency (52\%) when compared with a $10 \mathrm{~cm}$ cellulose pads system (70\%) when the void velocity of the bricks is equal to the face velocity of the cellulose pads $\left(3.9 \mathrm{~m} \mathrm{~s}^{-1}\right)$. However, if the number of porous media brick rows had been increased from 4 to 6 while holding the cooling efficiency per unit of media thickness constant at 1.3\% $\mathrm{cm}^{-1}$, it is possible that the T1 pozzolan system may have achieved a cooling performance similar to a single row $10 \mathrm{~cm}$ cellulose pad system $\left(1.3 \% \mathrm{~cm}^{-1} \times 6\right.$ rows $\times 10 \mathrm{~cm} \mathrm{row}^{-1}=$ estimated cooling efficiency of $\left.78 \%\right)$. However, it is yet unknown if the 
cooling efficiency per unit of media thickness remains constant as the number of brick rows is increased or decreased, as the

only configuration tested during the scope of this work was a four row configuration of T1 pozzolan bricks. Therefore, future work will be required to evaluate potential changes in cooling efficiency per unit of media thickness as both the media thickness and the number of rows of bricks increases or decreases.

\section{Evaporative CoOling Performance of TyPe 2 bricks}

Results of evaporative cooling using brackish water and $\mathrm{T} 2$ bricks, along with an existing onsite cellulose pads system, are shown in Table 4. The cooling systems were operating with brackish water having a TDS concentration of 2.7-3.3 ppt.

Table 4. Experimental results comparing cooling system performance at Gharbiya farms.

\begin{tabular}{|c|c|c|c|}
\hline & $\begin{array}{c}\text { Type } 2 \text { Pozzolan } \\
\text { Bricks Brackish Water } \\
\text { Evaporative Cooling } \\
\text { System at Gharbiya } \\
\end{array}$ & $\begin{array}{c}\text { Cellulose Pads } \\
\text { Brackish Water } \\
\text { Evaporative } \\
\text { Cooling System at } \\
\text { Gharbiya } \\
\end{array}$ & $\begin{array}{c}\text { Cellulose Pads } \\
\text { Freshwater } \\
\text { Evaporative } \\
\text { Cooling }{ }^{[a]} \\
\end{array}$ \\
\hline Number of porous media rows & 2 & 1 & 1 \\
\hline Total porous media thickness & $40 \mathrm{~cm}$ & $10 \mathrm{~cm}$ & $10 \mathrm{~cm}$ \\
\hline Space between rows & $6 \mathrm{~cm}$ & NA & NA \\
\hline Total evaporative cooling system thickness & $46 \mathrm{~cm}$ & $10 \mathrm{~cm}$ & $10 \mathrm{~cm}$ \\
\hline Face air velocity & $1 \mathrm{~m} \mathrm{~s}^{-1}$ & $2.8 \mathrm{~m} \mathrm{~s}^{-1}$ & $2.8 \mathrm{~m} \mathrm{~s}^{-1}$ \\
\hline Pressure drop & $53 \mathrm{~Pa}$ & $46 \mathrm{~Pa}$ & $52 \mathrm{~Pa}$ \\
\hline Average void air velocity & $5.4 \mathrm{~m} \mathrm{~s}^{-1}$ & NA & NA \\
\hline Temperature based cooling efficiency & $73 \%$ & $71 \%$ & $71 \%$ \\
\hline Pressure drop/media thickness & $1.3 \mathrm{~Pa} \mathrm{~cm}^{-1}$ & 4.6 $\mathrm{Pa} \mathrm{cm}^{-1}$ & $5.2 \mathrm{~Pa} \mathrm{~cm}^{-1}$ \\
\hline Cooling efficiency/media thickness & $1.8 \% \mathrm{~cm}^{-1}$ & $7.1 \% \mathrm{~cm}^{-1}$ & $7.1 \% \mathrm{~cm}^{-1}$ \\
\hline Porous media face area & $11.6 \mathrm{~m}^{2}$ & $4.2 \mathrm{~m}^{2}$ & NA \\
\hline
\end{tabular}

${ }^{[a]}$ Literature results (Koca et al., 1991).

Results from side by side system operation demonstrated that the two row T2 pozzolan brick system compared well to the cellulose pads system in terms of cooling efficiency ( $73 \%$ vs. $71 \%$ ) and pressure drop (53 Pa vs. $46 \mathrm{~Pa}$ ).

In this experimental setup, the pozzolan system was sized with a face area $\sim 2.7 \mathrm{x}$ larger than the cellulose pads system and installed on a greenhouse of identical size and construction. If the pozzolan system had been sized even larger, it is expected that the cooling efficiency would have slightly increased and the pressure drop would have decreased such that an equal pressure drop to the evaporative cooling system could have been achieved with a greater cooling efficiency. This expectation is based upon the fact that the velocity of the air through the bricks would have decreased, leading to a longer air/liquid contact time. From literature results with CPs, a lower air velocity through an evaporative cooling system gives a higher cooling efficiency with a corresponding lower pressure drop. (Malli et al., 2011) 


\section{DURABILITY OF POZZOLAN BRICKS USING SALT WATER FOR EVAPORATIVE COOLING}

While the Gharbiya system was only operated for a short period of time, the KAUST system was operated semi-continuously

211 from May 2013 through May 2017 (approximately 4 years). During this time, salt was intentionally precipitated from the 212 seawater onto the bricks at various times during the course of system operation (i.e., water was allowed to evaporate such that 213 salt levels exceeded their respective crystallization points). The precipitated salts were then removed via pressure washing 214 and/or manual scrubbing with a brush (Figure 8). No changes in system efficiency or structural degradation of the pozzolan 215 bricks were noted as a result of salt accumulation and subsequent removal/cleaning. During the same period, a cellulose pads 216 system utilizing fresh water at a greenhouse only $\sim 3 \mathrm{~km}$ away clogged with dust and salts and required replacement (Figure 1). 217 

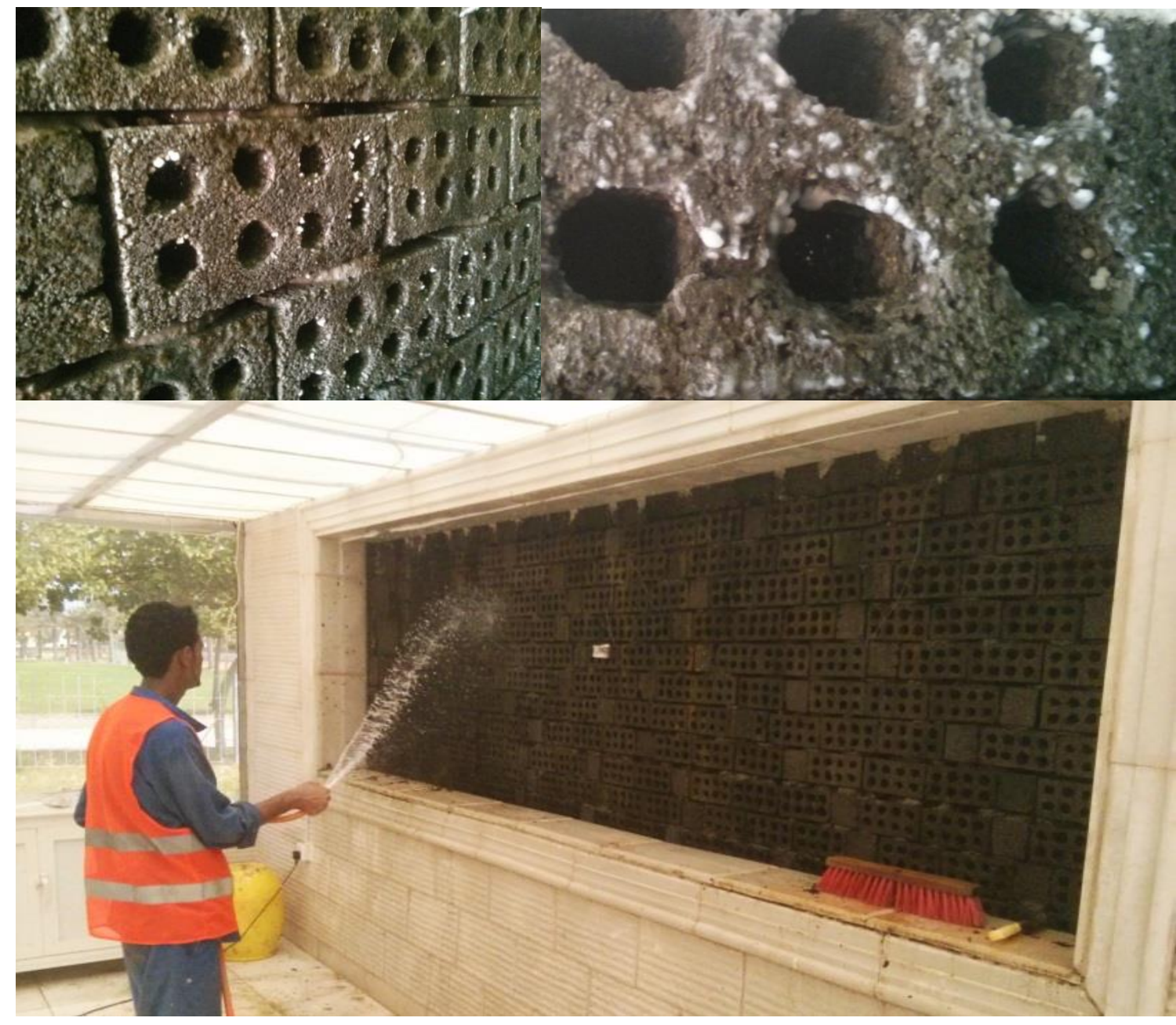

Figure 8. Sea salt accumulation and removal/cleaning from pozzolan bricks in KAUST full scale system.

\section{COMPARISON OF EVALUATED SYSTEMS}

223 The performance of the experimental systems varied based upon the design of the system, the type of bricks installed, and 224 the number of rows of bricks. Table 5 compares the design details and performance of the systems. 
Table 5. Comparison of pozzolan brick experimental system performance.

\begin{tabular}{ccc}
\hline & $\begin{array}{c}\text { KAUST } \\
\text { System }\end{array}$ & $\begin{array}{c}\text { Gharbiya } \\
\text { System }\end{array}$ \\
\hline Pozzolan brick type & 1 & 2 \\
Porous media face area & $24 \mathrm{~m}^{2}$ & $11.6 \mathrm{~m}^{2}$ \\
Number of porous media rows & 4 & 2 \\
Total porous media thickness & $40 \mathrm{~cm}$ & $40 \mathrm{~cm}$ \\
Space between rows & $10 \mathrm{~cm}$ & $6 \mathrm{~cm}$ \\
Total system thickness & $70 \mathrm{~cm}^{-1}$ & $46 \mathrm{~cm}^{-1}$ \\
Face air velocity & $0.5 \mathrm{~m} \mathrm{~s}^{-1}$ & $1 \mathrm{~m} \mathrm{~s}^{-1}$ \\
Total pressure drop & $17 \mathrm{~Pa}^{-1}$ & $53 \mathrm{~Pa}$ \\
Average void air velocity & $3.9 \mathrm{~m} \mathrm{~s}^{-1}$ & $5.4 \mathrm{~m} \mathrm{~s}^{-1}$ \\
Temperature based cooling efficiency & $52 \%$ & $73 \%$ \\
Pressure drop/media thickness & $0.43 \mathrm{~Pa} \mathrm{~cm}^{-1}$ & $1.3 \mathrm{~Pa} \mathrm{~cm}^{-1}$ \\
Cooling efficiency/media thickness & $1.3 \% \mathrm{~cm}^{-1}$ & $1.8 \% \mathrm{~cm}^{-1}$ \\
Surface area of air voids/media volume & $0.25 \mathrm{~cm}^{2} \mathrm{~cm}^{-3}$ & $0.31 \mathrm{~cm}^{2} \mathrm{~cm}^{-3}$ \\
\hline
\end{tabular}

In terms of cooling efficiency, the Gharbiya system with $\mathrm{T} 2$ bricks performed better, both in terms of overall efficiency $(73 \%$ vs. $52 \%)$ and in terms of efficiency per unit of media thickness $(1.8 \%$ per $\mathrm{cm}$ vs. $1.3 \%$ per $\mathrm{cm})$. This increase in cooling efficiency was expected, as the T2 bricks have $25 \%$ more surface area for air/liquid contact in the air passage holes when compared with the T1 bricks (conical $=0.25 \mathrm{~cm}^{2}$ of hole surface area per $\mathrm{cm}^{3}$ of media volume vs. cylindrical $=0.31 \mathrm{~cm}^{2}$ of hole surface area per $\mathrm{cm}^{3}$ of media volume). It should also be noted that this increase in cooling efficiency happened in spite of the fact that the average air velocity through the $\mathrm{T} 2$ bricks was faster $\left(5.4 \mathrm{vs.} 3.9 \mathrm{~m} \mathrm{~s}^{-1}\right)$. In the literature, it has been shown that a faster air velocity through CPs results in a lower cooling efficiency. (Malli et al., 2011) The fact that the T2 bricks performed better is likely due to the increased surface area in the air passage holes. The lower salinity of the brackish water used at Gharbiya ( $\sim 3 \mathrm{ppt})$ as compared with seawater used at KAUST ( $43 \mathrm{ppt})$ may have also contributed to the higher cooling efficiency, however, further experiments would be required to confirm how much effect the salinity of the water affected the cooling efficiency in comparison to the difference in brick design.

The KAUST system with T1 bricks had a much lower pressure drop (17 Pa) when compared with the Gharbiya system with T2 bricks (53 Pa). However, the KAUST system was sized with double the porous media face area, leading to a lower exit air velocity from the brick voids $\left(3.9 \mathrm{~m} \mathrm{~s}^{-1}\right.$ vs. $\left.8.1 \mathrm{~m} \mathrm{~s}^{-1}\right)$ and therefore a lower pressure drop. The exit air velocity of $8.1 \mathrm{~m} \mathrm{~s}^{-1}$ from the conical-shaped holes in the T2 brick design is higher than the average velocity of $5.4 \mathrm{~m} \mathrm{~s}^{-1}$ as shown in Table 5 because the diameter of the holes at the exit $(2 \mathrm{~cm})$ is smaller than the diameter of the holes at the entry $(3 \mathrm{~cm})$, as is shown in Figure 4. Based upon results with CPs recorded in literature, the expected pressure drop through an evaporative system increases by 
approximately $1.5 \mathrm{x}$ for every $1 \mathrm{x}$ increase in velocity through the system. (Malli et al., 2011) Using this relationship, the expected pressure drop at the KAUST system would have increased to $53 \mathrm{~Pa}$ if the exit air velocity had been increased to match that at the Gharbiya system $\left(8.1 \mathrm{~m} \mathrm{~s}^{-1}\right)$. Incidentally, this value matches exactly with the pressure drop measured at Gharbiya (53 Pa). When the cooling efficiency is considered and compared taking into account the pressure drop (cooling efficiency / pressure drop), the larger KAUST system provided higher efficiency per unit of pressure drop (3.1\% per Pa vs. 1.4\% per Pa). This metric is driven by the air velocity through the bricks, where a higher air velocity leads to a decline in cooling efficiency and a larger pressure drop. To achieve a lower air velocity through the bricks while maintaining the same total airflow through the cooling system, the size of the system can be increased (more face area). A larger system means more capital expense up front for installation, but is expected to result in a better overall cooling performance and lower long-term operating expense due to lower fan energy requirements to overcome pressure drop through the system while achieving the desired total airflow.

When the pozzolan systems are compared with cellulose pads adiabatic cooling systems, there are a several differences. Pozzolan brick systems have a lower cooling efficiency per unit volume than new CPs. Therefore, more volume of installed bricks is required to achieve a desired cooling efficiency when compared with CP. Construction of a pozzolan evaporative cooling system will require more surface area than a cellulose pads system to achieve the same cooling efficiency with the same fan flow rate. Care should be taken during design to size the pozzolan evaporative cooling systems appropriately. The face area of an evaporative cooling system using $\mathrm{T} 2$ bricks is recommended to be $\sim 2.5-3 \mathrm{x}$ larger than a cellulose pads system designed for the same airflow rate. Offsetting this, pozzolan brick systems have a lower pressure drop per unit of thickness when the void air velocity is taken into account. The necessary increase in porous media face area is also offset by the fact that the bricks are rigid, and as such can be incorporated into the structure of the building (i.e., they can be self-load bearing and are a long term solution). CPs, in contrast, must be supported by the building structure and replaced frequently. Unlike like cellulose pads systems, pozzolan brick systems are not damaged structurally if/when salt crystals precipitate in the system. Therefore, pozzolan brick systems can be considered more favorable for use with brackish or seawater than cellulose pads systems when/if salt precipitates on the evaporative cooling media. In addition, aggressive cleaning methods may be utilized when cleaning pozzolan brick systems.

Suggested future research beyond the proof of concept testing includes:

- Cooling efficiency varies with air velocity through the porous media. The studied installations only allow evaluation of cooling efficiency at one air velocity per site. Cooling efficiency of the bricks might be evaluated at other air velocities such that cooling efficiency vs. air speed curves can be generated for the pozzolan bricks similar to those curves found in other work, such as (Koca et al., 1991) (Malli et al., 2011).

- Pressure drop through the cooling system is directly related to energy requirements from the fan system and also structural design requirements for the greenhouse. No pressure drop vs. air speed curves have been generated for the 


\section{Conclusions}

To address concerns related to the clogging when using saline water, and to further enable the use of brackish and/or seawater

pozzolan bricks. Again, these curves could be developed similar to what is available for cellulose pads systems.

- A hybrid pozzolan brick/cellulose pads cooling system is suggested for evaluation. Pozzolan bricks are considered more favorable for use with brackish and/or seawater than CPs as it relates to maintenance and life expectancy. However, it is important to note that CPs have been used effectively for evaporative cooling with seawater, most recently by the Sahara Forest Project in Qatar and also by Seawater Greenhouse projects in Oman, Australia, and the Canary Islands. In conversations with staff from the Sahara Forest Project, it was noted that dust screens were useful to protect cellulose pads from clogging (V. Corless, Sahara Forest Project, personal communication, May 20, 2014). Therefore, it is suggested to build and test a hybrid pozzolan brick/cellulose pads cooling system utilizing seawater and/or brackish water, where the pozzolan bricks are used as the first contact evaporative cooling wall/dust screen and CPs are used as a second contact evaporative cooling wall where the salinity of the water is managed to prevent precipitation of salt crystals.

- Structurally, pozzolan bricks are very different from CPs. The bricks are rigid and have the potential to be used without support and/or in the structure of buildings and hedge fences. This may be one of the greatest advantages of the bricks, as it opens up doors for use in alternative applications where CPs would not be fit for purpose. However, the fundamental research into the structural capacity of the bricks is lacking. Loading capacity, responses to stress and strain, and long-term losses in structural integrity due to wear and tear from environmental conditions (including water and salt) have not been adequately evaluated.

for evaporative cooling in controlled environment agriculture such that significant fresh water savings can be achieved, two

pozzolan evaporative cooler brick designs were developed for proof of concept testing. T1 pozzolan bricks had air passage

holes that were cylindrical in shape, while T2 pozzolan bricks had air passage holes that were conical in shape, resulting in an

increase in surface area for air/liquid contact of $25 \%$. The pozzolan-based evaporative cooling medium was evaluated for

cooling efficiency, pressure drop, and resistance to harsh environments. As it relates to these considerations, T1 and T2

pozzolan bricks were applied in proof of concept testing for EC, achieving the following:

- Pozzolan bricks had a lower cooling efficiency per unit volume when compared with CP.

- Pozzolan bricks had a lower pressure drop per unit volume when compared with CP.

- $\quad$ T2 pozzolan provided a higher cooling efficiency when compared with T1 pozzolan bricks.

- Pozzolan bricks were not noticeably damaged by salt precipitation. The bricks were manually cleaned and continued to operate without losses in effectiveness. Therefore, the bricks are considered suitable for continuous use with brackish and seawater.

- The pozzolan evaporative cooling system at KAUST operated using seawater for 4+ years using seawater. Cellulose pads utilizing fresh water at a site only $\sim 3 \mathrm{~km}$ away required replacement during this same period due to clogging via dust and salts.

The completed work effectively proved the concept of using pozzolan bricks for evaporative cooling with saline water.

While the technology was empirically evaluated using sea and brackish water in Saudi Arabia, it has practical applications around the globe, as both saline water and pozzolan materials are available around the world. When applied in hot, dry climates, the technology has the potential to replace the use of fresh water in the evaporative cooler and reduce the water footprint of crops grown in controlled environment agriculture by $80-90 \%$. 


\section{ACKNOWLEDGEMENTS}

This work was supported by funding from King Abdullah University of Science and Technology (KAUST). The authors thank Eng. Mohammed Junaid and Mr. Babar Khan for their assistance in data collection and Gharbiya farms for their assistance and participation in the study. Thanks also to Eng. Mohammad Saleh Bajrai of the CODEC Ready Mix factory in Jeddah, Saudi Arabia for making the bricks and providing insight into the manufacturing process. A thanks is also owed to laboratory staff at the Center for Desert Agriculture (CDA), Water Desalination and Reuse Center (WDRC), and KAUST's Core Labs for their help with equipment and data analysis. Finally, thanks to staff at the KAUST Innovation and Economic Development for their work in supporting the development of the pozzolan brick technology.

\section{REFERENCES}

Ahmed, E. M., Abaas, O., Ahmed, M., \& Ismail, M. R. (2011). Performance evaluation of three different types of local evaporative cooling pads in greenhouses in Sudan. Saudi J. of Biol. Sci., 18(1), 45-51. doi:http://dx.doi.org/10.1016/j.sjbs.2010.09.005

Al-Madhoun, N. M. (2016). Climate control systems using pozzolan materials. World Intellectual Property Organization Patent Application PCT/IB2015/001639.

al-Swaidani, A. M., Aliyan, S. D., \& Adarnaly, N. (2016). Mechanical strength development of mortars containing volcanic scoria-based binders with different fineness. Eng. Sci. and Technol., 19(2), 970-979. doi:http://dx.doi.org/10.1016/j.jestch.2015.12.006

Dağtekin, M., Karaca, C., \& Yıldız, Y. (2009). Performance characteristics of a pad evaporative cooling system in a broiler house in a Mediterranean climate. Biosys. Eng., 103(1), 100-104.

Davies, P., \& Paton, C. (2004). The Seawater Greenhouse in the United Arab Emirates: Thermal Modelling and Evaluation of Design Options. Desalination, 173(2), 103-111.

Dawoud, B., Zurigat, Y. H., Klitzing, B., Aldoss, T., \& Theodoridis, G. (2006). On the possible techniques to cool the condenser of seawater greenhouses. Desalination, 195(1-3), 119-140. doi:10.1016/j.desal.2005.09.038

Ghaffour, N., Reddy, V. K., \& Abu-Arabi, M. (2011). Technology development and application of solar energy in desalination: MEDRC contribution. Renewable and Sustainable Energy Rev., 15(9), 44104415. doi:10.1016/j.rser.2011.06.017

Goosen, M. F. A., Sablani, S. S., Paton, C., Perret, J., Al-Nuaimi, A., Haffar, I., . . Shayya, W. H. (2003). Solar energy desalination for arid coastal regions: development of a humidification-dehumidification seawater greenhouse. Solar Energy, 75(5), 413-419. doi:10.1016/j.solener.2003.07.007

Gunhan, T., Demir, V., \& Yagcioglu, A. (2007). Evaluation of the suitability of some local materials as cooling pads. Bios. Eng., 96(3), 369-377.

He, J., \& Hoyano, A. (2010). Experimental study of cooling effects of a passive evaporative cooling wall constructed of porous ceramics with high water soaking-up ability. Building and Environ., 45(2), 461472. doi:10.1016/j.buildenv.2009.07.002

Johnson, D. W., Yavuzturk, C., \& Pruis, J. (2003). Analysis of heat and mass transfer phenomena in hollow fiber membranes used for evaporative cooling. J. of Membrane Sci., 227(1-2), 159-171. doi:http://dx.doi.org/10.1016/j.memsci.2003.08.023

Kellermeier, M., Glaab, F., Klein, R., Melero-Garcia, E., Kunz, W., \& Garcia-Ruiz, J. M. (2013). The effect of silica on polymorphic precipitation of calcium carbonate: an on-line energy-dispersive X-ray diffraction (EDXRD) study. Nanoscale, 5(15), 7054-7065. doi:10.1039/C3NR00301A Khan, M. I., \& Alhozaimy, A. M. (2010). Properties of natural pozzolan and its potential utilization in 
Koca, R. W., Hughes, W. C., \& Christianson, L. L. (1991). Evaporative cooling pads: test procedure and evaluation. Appl. Eng. Agric., 7.

Lakshtanov, L. Z., \& Stipp, S. L. S. (2010). Interaction between dissolved silica and calcium carbonate: 1. Spontaneous precipitation of calcium carbonate in the presence of dissolved silica. Geochimica et Cosmochimica Acta, 74(9), 2655-2664. doi:http://dx.doi.org/10.1016/j.gca.2010.02.009

Lefers, R., Bettahalli, N. M. S., Nunes, S. P., Fedoroff, N., Davies, P. A., \& Leiknes, T. (2016). Liquid desiccant dehumidification and regeneration process to meet cooling and freshwater needs of desert greenhouses. Desalination and Water Treatment, 57(48-49), 23430-23442. doi:10.1080/19443994.2016.1173383

Liao, C.-M., \& Chiu, K.-H. (2002). Wind tunnel modeling the system performance of alternative evaporative cooling pads in Taiwan region. Building and Environ., 37(2), 177-187. doi:http://dx.doi.org/10.1016/S0360-1323(00)00098-6

Liao, C. M., Singh, S., \& Wang, T. S. (1998). Characterizing the performance of alternative evaporative cooling pad media in thermal environmental control applications. J. of Environ. Sci. \& Health Part A, 33(7), 1391-1417.

Mahmoudi, H., Spahis, N., Abdul-Wahab, S. A., Sablani, S. S., \& Goosen, M. F. A. (2010). Improving the performance of a Seawater Greenhouse desalination system by assessment of simulation models for different condensers. Renewable and Sustainable Energy Rev., 14(8), 2182-2188. doi:10.1016/j.rser.2010.03.024

Mahmoudi, H., Spahis, N., Goosen, M. F., Sablani, S., Abdul-wahab, S. A., Ghaffour, N., \& Drouiche, N. (2009). Assessment of wind energy to power solar brackish water greenhouse desalination units: A case study from Algeria. Renewable and Sustainable Energy Rev., 13(8), 2149-2155. doi:10.1016/j.rser.2009.03.001

Malli, A., Seyf, H. R., Layeghi, M., Sharifian, S., \& Behravesh, H. (2011). Investigating the performance of cellulosic evaporative cooling pads. Energy Conversion and Manag., 52(7), 2598-2603. doi:http://dx.doi.org/10.1016/j.enconman.2010.12.015

Moufti, M. R., Sabtan, A. A., El-Mahdy, O. R., \& Shehata, W. M. (2000). Assessment of the industrial utilization of scoria materials in central Harrat Rahat, Saudi Arabia. Eng. Geol., 57(3-4), 155-162. doi:Doi 10.1016/S0013-7952(00)00024-7

Sabeh, N. C. (2007). Evaluating and Minimizing Water Use by Greenhouse Evaporative Cooling Systems in a Semi-Arid Climate. PhD Thesis, The University of Arizona, Tucson, Arizona.

Sablani, S. S., Goosen, M. F. A., Paton, C., Shayya, W. H., \& Al-Hinai, H. (2003). Simulation of fresh water production using a humidification-dehumidification seawater greenhouse. Desalination, 159, 283-288.

Snellings, R., Mertens, G., \& Elsen, J. (2012). Supplementary Cementitious Materials. Appl. Mineralolgy of Cement \& Concrete, 74, 211-278. doi:10.2138/rmg.2012.74.6

Tahri, T., Douani, M., Abdul-Wahab, S. A., Amoura, M., \& Bettahar, A. (2013). Simulation of the vapor mixture condensation in the condenser of seawater greenhouse using two models. Desalination, 317, 152159. doi:10.1016/j.desal.2013.02.025

Weert, F. v., Reckman, J., Gun, J. v. d., \& Kempen, C. M. v. (Cartographer). (2009). Global Overview of Saline Groundwater Occurrence and Genesis.

Wheeler, E. F., \& Both, A. J. (2002). Evaluating Greenhouse Ventilation Fan Capacity. 1st ed. Pennsylvania State University, Department of Agriculture and Biosystems Engineering.

Zamen, M., Amidpour, M., \& Firoozjaei, M. R. (2013). A novel integrated system for fresh water production in greenhouse: Dynamic simulation. Desalination, 322, 52-59. doi:10.1016/j.desal.2013.04.024 